\title{
Liberdades Políticas E NeCESSIDADES ECONÔMICAS EM AMARTYA SEN
}

\author{
Gabriela D'Ávila Schüttz*
}

Resumo: Este trabalho versa sobre as relações entre liberdades políticas e necessidades econômicas a partir de uma reflexão sobre a perspectiva do desenvolvimento como liberdade de Amartya Sen. O valor fundamental das liberdades substantivas para a satisfação das necessidades econômicas representa um aspecto crucial do pensamento seniano. Sen enfatiza a importância do papel constitutivo e instrumental das liberdades substantivas para o tratamento do problema das necessidades humanas, mas também para a discussão sobre o problema da conceituação das necessidades econômicas.

Palavras-chave: Amartya Sen, Liberdades Políticas, Necessidades Econômicas, Liberdades Substantivas.

Abstract: This paper verses upon the relation between political rights and economic needs after such reflection on the Amartya Sen's perspective of development as freedom. The fundamental value of the substantives freedoms to satisfy the economic needs is a crucial aspect of Sen's thinking. Sen emphasizes the importance of the constitutive and of instrumental role of freedoms to the treatment of the human needs' problem, but also to the debate about the problem of the conceptualization of economic needs.

Keywords: Amartya Sen, Political Rights, Economic Needs, Substantives Freedoms.

* Mestre em Economia social pela UNGS (Argentina) e mestre em Filosofia pela UNISINOS. E-mail: gschuttz@gmail.com. 
$|210|$

Liberdades políticas e necessidades..

\section{Introdução}

$\mathrm{O}$ presente artigo trata das inter-relações entre liberdades políticas e necessidades econômicas conforme a perspectiva da liberdade de Amartya Kumar Sen ${ }^{1}$ (1933). O valor fundamental das liberdades substantivas para a definição da ideia de necessidades econômicas representa um aspecto crucial do pensamento seniano relacionado à sua defesa de uma abordagem racional no âmbito da escolha social. Sen enfatiza o papel constitutivo e instrumental das liberdades substantivas e a importância da democracia para a satisfação de necessidades econômicas básicas, mas também para a discussão sobre o problema da conceituação das próprias necessidades econômicas. Neste sentido, tanto a resolução quanto a definição de necessidades econômicas estão atravessadas pela discussão pública, que por sua vez requer o respaldado de liberdades políticas e direitos civis que tornam possível o exercício da escolha social.

Este trabalho inicia apresentando a perspectiva da liberdade, destacando a diferenciação realizada por Sen do papel constitutivo e instrumental da liberdade. Em um segundo momento, são contrastadas três teses referente às relações entre liberdades políticas e necessidades econômicas, acompanhadas das respectivas réplicas segundo a interpretação seniana: (1) a tese de Lee, centralizada no crescimento econômico e supressão de liberdades políticas e direitos civis; (2) a tradução da pobreza como indiferença política, ou seja, defende-se que se for possível aos pobres escolher entre ter liberdades políticas e satisfazer necessidades econômicas, eles invariavelmente escolheriam a segunda alternativa; (3) a afirmação de que a ênfase sobre a liberdade política, os direitos civis e a democracia é uma prioridade especificamente ocidental. Assim, a submissão de decisões técnicas ao debate público corresponderia a um traço cultural e não a uma exigência de legitimidade ou uma parte constituinte da vida social, portanto,

\footnotetext{
${ }^{1}$ Filósofo moral e economista indiano laureado com o Prêmio de Ciências Econômicas em Memória de Alfred Nobel.
} 
podendo ser dispensada em outros contextos. Por fim, são discutidas algumas dificuldades e contribuições da proposta seniana.

\section{A perspectiva da liberdade}

As interrogações acerca do problema do desenvolvimento e a avaliação do bem-estar social ${ }^{2}$ empreendidas desde a década de 1970 por Amartya Sen nos brindam com a perspectiva do desenvolvimento como liberdade. Trata-se de um enfoque normativo para o desenvolvimento centralizado na expansão das liberdades substantivas da pessoa humana, como chave para a compreensão adequada de fenômenos sociais, tais como: a pobreza e a desigualdade social.

Sen refere-se às liberdades substantivas, como dimensões essenciais para o desenvolvimento de uma pessoa ou sociedade (educação básica, serviços elementares de saúde, acesso ao mercado, direitos civis e sociais, liberdade política, etc.), considerando que em situações de privação e de penúria as dificuldades em desenvolver-se, ser respeitado, poder frequentar diversos ambientes sociais sem constrangimento, possuir autoestima e participar da vida da comunidade se multiplicam.

Para Sen, as limitações reais de uma visão tradicional sobre o desenvolvimento e a satisfação das necessidades humanas não

\footnotetext{
${ }^{2}$ A questão do desenvolvimento e a avaliação do bem-estar social corresponde a dois problemas distintos, mas imbricados, envoltos em grandes debates devidamente registrados na literatura sobre o tema. Ver: Gersovitz et al.; (1982); Arrow et al. (2002), entre outros. Este artigo não tem como objetivo apresentar as principais discussões referentes a esses temas, mas destacar que tanto no âmbito das teorias do desenvolvimento econômico - das décadas de 1950 e 1960, independente da filiação teórica adotada (seja neoclássica ou marxista-cepalina) -, quanto da economia do bem estar, especialmente a questão da avaliação do bem-estar social, se orientam na direção da ampliação do crescimento econômico atrelado à ideia de maximização do bem-estar social.
} 
$|212|$

Liberdades políticas e necessidades...

surgem a partir da escolha de determinados meios para o crescimento econômico, mas no reconhecimento insuficiente de que o progresso econômico não é mais que um meio para outros objetivos. Em outras palavras, a deficiência mais importante do enfoque do desenvolvimento econômico (independente da orientação teórica) é a concentração sobre o rendimento do produto nacional bruto (PNB), em vez dos direitos da pessoa humana e os recursos que esses direitos geram (Sen, 1993, p. 753-754).

A perspectiva seniana do desenvolvimento como liberdade se insere na tradição aristotélica, na qual a riqueza, como observou Aristóteles em Ética a Nicômaco, "evidentemente não é o bem que estamos buscando, sendo ela meramente útil e em proveito de alguma coisa" (apud Sen, 2010, p. 28). Ao formular sua abordagem sobre o desenvolvimento, Sen rechaça às interpretações tradicionais centradas no crescimento econômico, pois a riqueza não pode ser considerada como um fim em si mesmo, mas tão somente um meio, "meramente útil e em proveito de alguma coisa".

Neste sentido, as proposições típicas utilizadas nessas análises dependem de combinar comportamento autointeressado, de um lado, e julgar a realização social segundo algum critério fundamentado na utilidade, de outro. No caso especifico do desenvolvimento econômico, a noção de crescimento econômico ocupa posição privilegiada na discussão, sendo empregada como sinônimo de desenvolvimento ou como condição necessária, mas não suficiente, dada à inclusão do aspecto distributivo na discussão. Embora o problema das desigualdades sociais apareça efetivamente em algumas dessas elaborações, o reconhecimento da insuficiência do crescimento econômico para o combate dos diversos tipos de privação desde uma concepção do bem-estar social baseada na liberdade, e não tendo como critério último a utilidade (independente como ela é caracterizada: prazer, satisfação ou renda e bens-primários), constitui-se em uma das mais significativas contribuições senianas para essa discussão. Deste modo, a principal diferença entre outros autores que já incluíam os tema da desigualdade social e justiça distributiva e a relativização da importância do crescimento econômico na discussão sobre o desenvolvimento e a avaliação do bem-estar social e a perspectiva formulada por Sen reside na ênfase sobre a liberdade. 
Sen questiona o desejo pela riqueza em si, e alega que as diversas razões que nos impulsionam a desejar mais renda e riqueza se relacionam com o fato de que sua posse nos permite, em muitos casos, termos mais liberdades. Sen considera que: “a utilidade da riqueza está nas coisas que ela nos permite fazer as liberdades substantivas que ela nos ajuda a obter"(Sen, 2010, p. $28-29)^{3}$.

Conforme Sen, trata-se de uma confusão no plano dos princípios atribuir à opulência o estatuto de objetivo a alcançar. A perspectiva seniana decorre, portanto, da ideia simples, mas potente, de que a 'riqueza não tem valor em si mesmo' ela não garante direitos nem liberdades, tampouco a satisfação de necessidades e desejos que as pessoas podem ter razão para estimar.

${ }^{3}$ Segundo Sen (2010, p. 41), “as conexões aristotélicas são suficientemente óbvias. (O enfoque de Aristóteles sobre "florescimento" e "capacidade" [capability] relaciona-se claramente à qualidade de vida e às liberdades substantivas, como foi discutido por Martha Nussbaum"). Sen assinala que foi Martha Nussbaum $(1988 ; 1992)$ quem melhor tratamento deu a natureza aristotélica da perspectiva do desenvolvimento como liberdade e da abordagem avaliatória que dela decorre: o enfoque das capabilidades [Capability approach]. Além de Aristóteles, há também fortes conexões com as análises de Adam Smith sobre necessidades, condições de vida, comportamento humano e sentimentos morais (Sen, 2008).

${ }^{4}$ Isto não significa aceitar tudo o que a pessoa preza como sendo valioso incondicionalmente e tão intensamente quanto isso é valorizado pela pessoa (Sen, 2008, p. 58), mas respeitar o espaço da liberdade da pessoa para alcançar o que quer, como agente livre e responsável. O uso da liberdade própria do agente é, em um sentido importante, uma questão para ser julgada pela pró pria pessoa, a partir da necessidade de uma avaliação cuidadosa de metas, objetivos, lealdades e obrigações e - em um sentido amplo - de sua concepção do bem. Aliado a isso, as pessoas devem entrar na contabilidade moral de outras, não apenas como indivíduos cujo bem-estar exige preocupação, mas também como pessoas cuja condição de agente livre e responsável deve ser reconhecida (Sen, 1985, pp. 203-204). Deste modo, o enfoque seniano admite uma série de objetivos e metas perseguidos por indivíduos motivados por princípios 
$\mid 214$ |

Liberdades políticas e necessidades..

Na perspectiva do desenvolvimento como liberdade, a expansão de nossas liberdades substantivas é o que torna efetivamente nossa vida mais rica e mais desimpedida. Além disso, as liberdades substantivas são "componentes constitutivos do desenvolvimento. Sua relevância para o desenvolvimento não tem de ser estabelecida a posteriori, com base em sua contribuição indireta para o crescimento do PNB ou para a promoção da industrialização" (Sen, 2010, p. 19).

Para Sen, o que as pessoas conseguem positivamente realizar é diretamente influenciado pelas oportunidades econômicas, liberdades políticas, poderes sociais e por condições habilitadoras como a educação e a saúde.

As disposições institucionais que proporcionam essas oportunidades são ainda influenciadas pelo exercício das liberdades das pessoas, mediante a liberdade para participar da escolha social e da tomada de decisões públicas que impelem o progresso dessas oportunidades (Sen, 2010, p. 18).

Trata-se de uma relação de mão dupla entre "as disposições sociais que visam expandir as liberdades individuais e o uso das liberdades individuais não só para melhorar a vida de cada um, mas também para tornar as disposições sociais mais apropriadas e eficazes" (Sen, 2010, pp. 48-49). Dito de outra forma, ter mais liberdade permite com que as pessoas tenham mais potencial para cuidar de si mesmas e para influenciar o mundo.

Para Sen, "ver o desenvolvimento como expansão de liberdades substantivas dirige à atenção para os fins que o tornam

pluralistas, cujos resultados podem ir além do aumento da riqueza ou bem-estar. "Por exemplo, se uma pessoa lutar arduamente pela independência de seu país e quando essa independência for alcançada a pessoa ficar mais feliz, a principal realização é a independência, da qual a felicidade por essa realização é apenas uma conseqüência" (Sen, 2008, p. 60). 
importante, em vez de restringi-la a alguns meios que, inter alia, desempenham um papel relevante no processo" (Sen, 2010, p. 16). Portanto, a simples possessão de bens - a opulência - não pode ser o indicador real de desenvolvimento ou bem-estar, porque entre ter bens e o que se pode fazer com eles há uma variedade de fatores pessoais e sociais que interferem no resultado final obtido ${ }^{5}$, fazendo com que ele varie muito de pessoa para pessoa ${ }^{6}$. Sendo assim, Sen defende que qualquer relação causal que se estabeleça apoiando-se na ideia de que o crescimento econômico é capaz de promover per se o bem-estar social é equivocado.

Sen insiste no valor substantivo da liberdade como chave para a compreensão do problema do desenvolvimento e da avaliação do bem-estar social, pois considera que a renda e riqueza (ou bens primários), não correspondem ao bem que estamos

\footnotetext{
${ }^{5}$ A sensibilidade à distribuição e conversão de recursos não é uma preocupação exclusivamente seniana. Ao contrário, ela tem sido muito debatida, principalmente, a partir das contribuições de John Rawls (2000; 2002). Conforme Maric (1996) e Kolacinski (2001), não há dúvidas em relação à influência rawlsiana sobre o pensamento seniano e o reconhecimento por parte de Sen dos avanços obtidos em matéria de programas e políticas públicas para o desenvolvimento e o bem-estar social, através das contribuições da Teoria da Justiça de John Ralws (1971). No entanto, Sen afasta-se de Rawls e demais autores liberais e libertários [libertarian] ao insistir na diferença entre a ideia da liberdade "como o principal fim e o principal meio do desenvolvimento" (Sen, 2010, p. 10), e os demais meios para a liberdade (tais como: bens primários ou recursos que ajudam as pessoas a conseguir mais liberdade), mas que não representam a liberdade em si, e tampouco sua conversão na direção da expansão da liberdade é garantida.

${ }^{6} \mathrm{O}$ autor se refere a vários casos para ilustrar seu argumento, entre eles o fato de que "mesmo em países muito ricos, às vezes a longevidade de grupos substanciais não é mais elevada do em que muitas economias mais pobres do chamado Terceiro Mundo" (Sen, 2010, p. 29). A análise do caso dos afro-americanos nos Estados Unidos corrobora essa perspectiva em favor de uma análise mais ampla das relações entre privação e riqueza, ao demonstrar como embora essa população seja muitíssimo
} 
$|216|$

Liberdades políticas e necessidades...

buscando, sendo eles meramente úteis e em proveito de alguma coisa. Eles não são intrinsecamente bons ou valiosos, apenas contribuem para alguma outra coisa. Assim, uma investigação valorativa acerca do sentido do desenvolvimento e do bem-estar (enquanto florescimento humano) deve fundamentar a sua análise naquilo que melhor apreende e traduz os objetos e estados valiosos por si mesmos: as liberdades substantivas.

\section{Dois papéis da liberdade}

Conforme Sen, muitas das confusões em torno do desenvolvimento e da satisfação das necessidades humanas, incluindo as necessidades econômicas, ocorrem devido à compreensão errônea de certos conceitos. Para Sen, a consideração do valor intrínseco da liberdade humana em geral é insuficiente "para uma compreensão mais plena da relação entre desenvolvimento e liberdade, precisamos ir além desse reconhecimento básico"(Sen, 2010, p. 10). Neste sentido, mesmo que a ideia da expansão das liberdades substantivas esteja no coração de sua teoria, precisamos distinguir claramente o papel constitutivo e instrumental da liberdade, como parte central do processo de ampliação de nossa visão sobre as necessidades humanas.

mais rica (considerando as diferenças de custo de vida) do que os habitantes do estado de Kerala, na Índia, tanto os homens quanto as mulheres indianas superam as perspectivas de sobrevivência dos afroamericanos. Segundo Sen, a renda é obviamente uma questão importante na caracterização da pobreza, mas na discussão sobre a pobreza americana, em geral, e dos afro-americanos, em particular, muitas vezes são perdidas dimensões importantes por causa de uma concentração sobre o rendimento. Portanto, a natureza e a extensão da privação entre afro-americanos não pode ser adequadamente compreendida quando são medidos pelo critério da renda. Neste caso a violência é uma parte significativa da carência social (Sen, 1993, pp. 45-47). Essas comparações e outras do gênero são apresentadas em Sen (1981; 1995). 
O papel constitutivo da liberdade refere-se àquelas atividades que por si mesmas enriquecem a vida humana. A liberdade política e as liberdades civis, por exemplo, "são importantes por si mesmas, de um modo direto; não é necessário justificá-las indiretamente com base em seus efeitos sobre a economia" (Sen, 2010, p. 31). Ocorre, muitas vezes, a consideração apenas instrumental de uma liberdade. Porém, para Sen, mesmo que um conjunto de liberdades atue de forma a potencializar outras liberdades, isso não significa que elas não têm valor em si mesmo. Do mesmo modo que, "o valor intrínseco de qualquer atividade não é uma razão adequada para menosprezar seu papel instrumental" (Sen, 2008, p. 91).

Para Sen, ampliamos nossa compreensão sobre a importância das liberdades substantivas para o desenvolvimento, quando consideramos seu papel constitutivo para a vida humana e, ao mesmo tempo, reconhecemos a eficácia do papel instrumental de liberdades específicas para a promoção de liberdades de outros tipos.

Em sua abordagem, Sen concentra-se particularmente no papel instrumental e nas inter-relações de um conjunto de cinco liberdades substantivas: (1) liberdades políticas, (2) facilidades econômicas, (3) oportunidades sociais, (4) garantias de transparência e (5) segurança protetora.

As liberdades políticas, incluindo os direitos civis, "referem-se às oportunidades que as pessoas têm para determinar quem deve governar e com base em que princípios" (Sen, 2010, p. 58). Inclui a possibilidade de fiscalizar e criticar as autoridades, ter liberdade de expressão política e uma impressa sem censura. Neste caso, mesmo que a pessoa não tem interesse imediato em exercer esses direitos, ainda assim a ausência deles configura-se uma privação de sua liberdade, pois é preciso garantir a possibilidade de escolha.

Sobre as facilidades econômicas, Sen descreve-as como "oportunidades que os indivíduos têm para utilizar recursos econômicos com propósitos de consumo, produção e troca" (Sen, 2010, p. 59). Depende dos recursos disponíveis, das condições de 
$|218|$

Liberdades políticas e necessidades...

troca, dos intitulamentos ${ }^{7}$ econômicos de que uma pessoa dispõe como acesso ao crédito, disponibilidade de financiamento, etc.

Oportunidades sociais "são as disposições que a sociedade estabelece nas áreas de educação, saúde, etc., as quais influenciam a liberdade substantiva de o individuo viver melhor" (Sen, 2010, p. 59). Correspondem ao acesso à educação, mercado, participação política e realização social. Por exemplo, pessoas privadas de educação podem ser excluídas do mercado de trabalho e demais atividades econômicas que requeiram qualificação profissional e conhecimento técnico. "De modo semelhante, a participação política pode ser tolhida pela incapacidade de ler jornais ou de comunicar-se por escrito com outros indivíduos envolvidos em atividades políticas" (Sen, 2010, p. 60).

As garantias de transparências desempenham um papel instrumental como inibidoras da corrupção, da irresponsabilidade financeira, ambiental, social e transações ilícitas. Toda sociedade opera com alguma presunção básica de confiança. "Quando essa confiança é gravemente violada, a vida de muitas pessoas - tanto as envolvidas diretamente como terceiros - pode ser afetada negativamente" (Sen, 2010, p. 341). A formação de valores e

\footnotetext{
${ }^{7} \mathrm{O}$ termo inglês Entitlement é empregado por Amartya Sen com um significado muito específico, explicitado em seu livro escrito em coautoria com Jean Drèze, Hunger and public action (1989): “o 'entitlement' de uma pessoa é representado pelo conjunto de cestas de bens que podem ser adquiridos mediante o uso de vários canais legais de aquisição facultados a essa pessoa. Em uma economia de mercado com propriedade privada, o conjunto de 'entitlement' de uma pessoa só é determinado pelo pacote original de bens que ela possui (denominado 'dotação') e pelas várias cestas alternativos que ela pode adquirir, começando com cada dotação inicial, por meio de comércio e produção (denominado seu 'entitlement de troca'). Uma pessoa passa fome quando seu 'entitlement' não inclui, no conjunto [que é formado pelas cestas alternativas de bens que ela pode adquirir], nenhum pacote de bens que contenha uma quantidade adequada de alimento" (Sen, 2010, p. 57).
} 
comprometimentos comuns por meio da discussão pública pode impedir que pessoas, organizações e empresas - talvez até mesmo Estados -, venham a sucumbir em ações desonestas. De acordo com Sen, valores morais e códigos de comportamento nas relações econômicas funcionam um pouco como o oxigênio: "passamos a sentir interesse pela sua presença quando ele está ausente" (Sen, 2010, p. 336). Portanto, "para funcionar, o sistema de mercado requer disposições visando impedir que uma parte lese as outras" (Sen, 2010, p. 341).

Por fim, independente da forma de governo ou sistema econômico, há possibilidade de que algumas pessoas encontrem-se no limiar da vulnerabilidade, em casos extremos ou apenas temporariamente impedidas de exercerem suas atividades. "A segurança protetora é necessária para proporcionar uma rede de segurança social, impedindo que a população afetada seja reduzida à miséria abjeta e, em alguns casos, até a morte" (Sen, 2010, p. 60). Inclui benefícios aos desempregados e suplementos de renda regulares para os indigentes (disposições institucionais fixas), bem como, distribuição de alimentos e outras ações sazonais, conforme gravidade do cenário. Grandes desastres naturais ou uma grave crise econômica estão entre os fenômenos que devem cobertos pela segurança protetora com medidas ad hoc.

Segundo Sen, uma vez resguardadas essas condições, os indivíduos deixam de ser beneficiários passivos do desenvolvimento, para se tornarem agentes livres e responsáveis pelo seu próprio destino. Portanto, é sumamente importante analisar as disposições institucionais e oportunidades existentes, concentrando-se no aumento da liberdade que elas oferecem às pessoas:

Liberdades políticas (na forma de liberdade de expressão e eleições livre) ajudam a promover segurança econômica. Oportunidades sociais (na forma de serviços de educação e saúde) facilitam a participação econômica. Facilidades econômicas (na forma de oportunidades de participação no comércio 
$|220|$

Liberdades politicas e necessidades..

e na produção) podem ajudar a gerar abundância individual, além de recursos públicos para os serviços sociais. Liberdades de diferentes tipos podem fortalecer umas às outras (Sen, 2010, p. 26).

Deste modo, Sen ressalta que "a importância intrínseca da liberdade humana como o objetivo preeminente do desenvolvimento precisa ser distinguida da eficácia instrumental da liberdade de diferentes tipos na promoção da liberdade humana" (Sen, 2010, p. 56).

\section{Democracia e crescimento econômico}

A defesa veemente das liberdades políticas e direitos civis básicos presentes na tradição do pensamento liberal, corrente filosófica da qual Sen é partidário ${ }^{8}$, não foi suficientemente capaz de convencer os setores mais conservadores da sociedade sobre a importância da salvaguarda das liberdades individuais. $\mathrm{O}$ reconhecimento das liberdades políticas e direitos civis para o enriquecimento da vida humana ocorreu de modo controverso e de forma alguma sua importância foi evidente nos círculos políticos e programas e políticas públicas para o desenvolvimento predominantes no século XX.

O tratamento dado ao problema das necessidades econômicas e sua relação com as liberdades políticas e os direitos civis básicos refletiu-se em uma fraca valoração da democracia,

\footnotetext{
${ }^{8}$ Filiar Sen a uma escola de pensamento não é algo simples. As polêmicas travadas com autores do chamado liberalismo igualitário - de "John Rawls (igual liberdade e igualdade na distribuição de 'bens primários'), Ronald Dworkin ('tratamento como iguais', 'igualdade de recursos'), Thomas Nagel ('igualdade econômica'), Thomas Scanlon ('igualdade'), e outras geralmente associadas com uma visão 'pró-igualdade' -", e ao Libertarismo (libertarianism), por exemplo, Robert Nozick, dificultam a aproximação de Sen a essas correntes (Sen, 2001, p. 44; 1980). De qualquer forma, parece haver consenso sobre as contribuições de Sen ao pensamento liberal como um todo.
} 
muitas vezes subjugada em detrimento de um suposto benefício para o crescimento econômico. Nesse contexto, a importância da democracia estava atrelada a sua capacidade de promover ou retardar o crescimento econômico.

A crença na denominada tese de Lee - em referência ao ex- primeiro ministro de Cingapura, no período de 1959 a 1990, Lee Kuan Yew -, é um exemplo do modo como com certa frequência a negação de liberdades políticas e direitos civis foi conduzida em nome de um suposto reflexo positivo para a economia de um país. Em linhas gerais, a tese de Lee afirma que a supressão de liberdades políticas e direitos civis básicos ajuda a estimular o desenvolvimento econômico e é benéfica para o crescimento econômico rápido. (Sen, 2010, pp. 30; 196-197; 199-200).

Desde a década de 1950, vários estudos vêm sendo elaborados com o objetivo de examinar as relações entre regimes políticos e crescimento econômico (Barros, 1990; Rao, 1984; O'Donnel, 1973). Contudo, para Przeworski e Limongi, "em certo sentido, os críticos e os defensores da democracia travam um diálogo de surdos", pois as evidências estatísticas apresentadas não oferecem informações conclusivas, tampouco apontaram de modo razoável para uma ou outra tendência ${ }^{9}$. Przeworski e Limongi concluíram que "ambos os argumentos podem ser verdadeiros" e que na verdade "conhecemos pouco sobre os determinantes do crescimento em geral". Desse modo, "o que faz a diferença não é a democracia ou o autoritarismo per se, e sim alguma outra coisa" (Przeworski e Limongi, 1997, pp. 183 e 188).

Esses estudos, em sua maioria, adotam uma visão do desenvolvimento análoga ao crescimento econômico, em que o bem-estar social é definido como utilidade, e não no sentido de liberdades substantivas que as pessoas realmente têm. Esta diferença não é nada sutil, uma vez que valorizar a democracia

${ }^{9}$ Dos dezoito estudos examinados pelos autores: oito concluíram em favor da democracia, oito em favor do autoritarismo, e cinco não apontaram qualquer diferença (Przeworski e Limongi, 1997). 
$|222|$

Liberdades políticas e necessidades...

intrinsecamente resulta em uma perspectiva muito diferente da ideia de desenvolvimento. Portanto, um ponto crucial dessa discussão consiste na indagação referente aos meios e os fins do desenvolvimento.

Sen (2010, p. 51) defende que "ver o desenvolvimento a partir das liberdades substantivas das pessoas tem implicações muito abrangentes para nossa compreensão do processo de desenvolvimento e também para os modos e meios de promovê-lo". Sen concorda com o absurdo da discussão mencionada por Przeworski e Limongi, mas por motivos completamente diferentes. Sen entende que a democracia é um elemento crucial para essa discussão e, além disso, não há razão suficiente que justifique a centralização do problema do desenvolvimento na esfera econômica. Segundo Sen, pensar no crescimento econômico como critério último para este tipo de avaliação, significa partir de uma visão muito restrita das potencialidades humanas.

Para Sen (2010, p. 23), quando a ênfase do desenvolvimento recai sobre a liberdade é possível ampliarmos nossa visão sobre as privações e considerarmos também aqueles casos no quais o aumento da renda não implica necessariamente no aumento das liberdades, assim como, reconhecer que "a privação de liberdade econômica pode gerar a privação de liberdade social, assim como a privação de liberdade social ou política pode, da mesma forma, gerar privação de liberdade econômica" (Sen, 2010, p. 23). Essas nuances dificilmente são consideradas desde abordagens sobre o desenvolvimento baseadas no crescimento econômico.

Para Sen, as verdadeiras questões que tem que ser abordadas envolvem a observação das inter-relações "entre liberdades políticas e a compreensão e satisfação das necessidades econômicas", pois "nossa conceituação de necessidades econômicas depende crucialmente de discussões e debates públicos abertos, cuja garantia requer que se faça questão da liberdade política e de direitos civis básicos" (Sen, 2010, p. 195).

Portanto, Sen fundamenta sua defesa em favor da democracia a partir de apreciação de três diferentes considerações 
sobre as liberdades políticas: (1) "sua importância direta para a vida humana associada a capacidades [capabilities] ${ }^{10}$ básicas (como a capacidade de [capability to] participação política e social)"; (2) seu papel instrumental "de aumentar o grau em que as pessoas são ouvidas quando expressam e defendem suas reivindicações de atenção política (como reivindicações de necessidades econômicas)"; (3) seu papel construtivo "na conceituação de necessidades (como compreensão das necessidades econômicas em um contexto social)" (Sen, 2010, p. 195).

Deste modo, Sen rejeita repetidamente a ideia de que existem prioridades econômicas capazes de justificar o sacrifício de certas liberdades. Segundo Sen, não há razões plausíveis para conjecturar a existência conflitiva entre liberdades políticas e crescimento econômico, pois tanto as evidências empíricas quanto a literatura especifica ${ }^{11}$ sobre o assunto "indicam veementemente que o crescimento econômico está mais ligado a um clima econômico mais propício do que a um sistema político mais rígido" (Sen, 2010, p. 30).

Por outro lado, as contribuições da democracia são múltiplas. “Nossas ideias sobre o que é justo e o que não é podem

\footnotetext{
${ }^{10} \mathrm{O}$ conceito de Capabilidade [capability] é termo seniano que reflete as liberdades substantivas da pessoa: "P é capaz de fazer x se, dada à oportunidade de fazer $x$, também poderia escolher deixar de fazer $x$ ". As capabilidades se vinculam às oportunidades, pois "condições externas para realizar funcionamentos precisam ser de algum modo incluídas como componentes das capabilidades". Deste modo, capabilidade não significa o mesmo que capacidade [ability], "como quando se diz que "A pessoa $\mathrm{P}$ é capaz de nadar", porque neste sentido, "capacidade" não implica "oportunidade": P pode ser capaz de nadar mesmo sem ter a oportunidade de nadar" (Sen, 2008b, p. 234). A capabilidade reflete a liberdade da pessoa para escolher entre diferentes estilos de vida e desta forma, envolve certa concepção da vida como uma combinação de várias atividades e modos de ser que uma pessoa pode considerar valiosa (Sen, 1993).

${ }^{11} \mathrm{O}$ autor se refere, em especial, aos seguintes estudos: Przeworski et al. (1995); Barro (1996); Helliwell (1994), entre outros.
} 
| 224 |

Liberdades políticas e necessidades...

ser influenciadas pelos argumentos apresentados para discussão pública", diz Sen, ao defender que "as disposições sociais surgidas do consenso e as políticas públicas adequadas não requerem que haja uma ordenação social única que contenha um ranking de todas as possibilidades sociais alternativas". Neste sentido, a formação de preferências, valores e comprometimentos comuns por meio da interação social e de acordos parciais nos proporcionam a vantagem de distinguir opções aceitáveis (eliminando as inaceitáveis), oferecendo soluções viáveis, que podem "basear-se na aceitação contingente de medidas específicas, sem exigir a unanimidade social completa", e ainda menos sua imposição desde governos autoritários (Sen, 2010, p. 323).

Além disto, ainda que o processo de desenvolvimento econômico eleve a renda e a riqueza de um país, isso poder não corresponder ao aumento de intitulamentos econômicos da população. Conforme Sen, a relação entre esses dois fatores está sujeita ao modo como as rendas geradas são distribuídas, “o principal é que o impacto do crescimento econômico depende muito do modo como seus frutos são aproveitados" (Sen, 2010, p. 66). Neste sentido, a contribuição do crescimento econômico tem de ser julgada não apenas pelo aumento das rendas privadas, mas também pela expansão de serviços sociais que o crescimento econômico pode possibilitar, por exemplo, através do financiamento de programas e políticas públicas.

Sen também analisa as inter-relações entre democracia e crescimento econômico a partir do exame dos processos casuais que estão envolvidos no desenvolvimento e crescimento econômico. Conforme Sen, as políticas e circunstâncias econômicas que conduziram ao êxito os países do Leste Asiático são hoje em dia razoavelmente bem compreendidas. Embora diferentes estudos empíricos tenham ênfases diversas, existe atualmente um razoável consenso quanto a uma lista geral de políticas exitosas aplicadas nesses países, incluindo abertura à concorrência, uso de mercados internacionais, alto nível de alfabetização e educação escolar, reformas agrárias bem-sucedidas, etc. 
Conforme Sen, à medida que o progresso econômico rápido dessas economias vai sendo mais plenamente analisado, torna-se cada vez mais claro que seus alicerces foram assentados em mudanças sociais positivas que resultaram na expansão de algumas liberdades substantivas. As mudanças sociais em questão (expansão da alfabetização, dos serviços, básicos de saúde e a reforma agrária) incidiram não somente sobre o aumento da produtividade e das possibilidades de emprego das pessoas envolvidas, mas também melhoraram efetivamente as condições de vida da população. Nestes casos, o que se verifica não são tanto as consequências sociais de reformas econômicas, mas as consequências econômicas de reformas sociais (Sen, 2010, pp. 198; 330-331).

\title{
Pobreza, liberdades políticas e direitos civis
}

Sen refuta outro argumento frequentemente utilizado para a justificação da prioridade total do progresso econômico sobre quaisquer outros direitos: o descaso dos pobres em relação aos seus direitos políticos. Trata-se da ideia de que se for possível aos pobres escolher entre ter liberdades políticas e satisfazer necessidades econômicas, eles invariavelmente escolheriam a segunda alternativa. Embora, a força desse argumento tenha sido suavizada nos últimos anos, a legitimidade alcançada nas décadas anteriores foi alarmante e, portanto, sua contestação segue sendo pertinente, principalmente porque seus ecos ainda ressoam em vários lugares do globo.

\begin{abstract}
Essa é uma linha de análise bem estabelecida, e foi veementemente defendida em Viena ${ }^{12}$ pelas delegações oficiais de diversos países em desenvolvimento, encabeçados por China, Cingapura e outros países do Leste Asiático, mas não objetada pela Índia ou outros países da Ásia meridional e ocidental, nem pelos governos
\end{abstract}

${ }^{12}$ Conferência de Viena sobre Direitos Humanos, de 1993. 
| 226 |

Liberdades políticas e necessidades...

africanos. Existe nessa linha de análise a retórica frequentemente repetida: o que deve vir primeiro eliminar a pobreza e a miséria ou garantir liberdade política e direitos civis, os quais afinal de contas, têm pouca serventia para os pobres? (Sen, 2010, p. 194)

Sen contesta essa ideia de várias maneiras. Primeiro, admitindo-se que a resposta presumida à pergunta mencionada é correta, e que as pessoas têm razão para querer eliminar, antes de mais nada, a privação econômica e a miséria, nada leva a crer que elas têm razões para abdicar de liberdades fundamentais e direitos básicos, tampouco que a intensidade das necessidades econômicas diminua a importância das liberdades políticas.

Segundo Sen (1999, p. 9), existe muito pouca evidência de que as pessoas pobres, dada à escolha, preferem rejeitar a democracia. Sen faz referência ao governo indiano, sob a liderança de Indira Gandhi ${ }^{13}$, que em meados da década de 1970 tentou usar um argumento semelhante à tese de Lee para justificar a supressão de vários direitos civis e políticos. Quando a eleição foi chamada, os eleitores dividiram-se precisamente sobre esta questão. Naquela disputa eleitoral, a questão decisiva foi travada em boa medida em torno da aceitabilidade da "emergência" da questão econômica contra a supressão dos direitos políticos e civis, que foi firmemente rejeitada. O eleitorado indiano - um dos mais pobres do mundo - mostrou-se ser nada menos interessado em protestar contra a negação das liberdades e direitos fundamentais que em reclamar da privação econômica. Para Sen à medida que tenha havido qualquer teste da proposição de que os pobres não se importam sobre direitos civis e políticos, a prova é totalmente contra essa alegação.

A presumida existência de um profundo conflito entre liberdades políticas e a satisfação das necessidades

\footnotetext{
${ }^{13}$ Indira Priyadarshini Gandhi (1917-1984), primeira mulher a ocupar o cargo de chefe do governo indiano, foi primeira-ministra da Índia entre 1966 e 1977 e entre 1980 e 1984.
} 
econômicas constitui uma premissa importante desse silogismo e, nesse sentido, essa variante do segundo argumento é dependente do primeiro (ou seja, da veracidade da tese de Lee) (Sen, 2010, p. 196).

Porém, como vimos, a veracidade dessa tese é altamente questionável. Sen afirma que "na verdade, há poucas evidências gerais de que um governo autoritário e a supressão de direitos políticos e civis sejam realmente benéficos para incentivar o desenvolvimento econômico" (Sen, 2010, p. 197). Por outro lado, "se o desenvolvimento é entendido de forma mais ampla, com ênfase nas vidas humanas, então se torna imediatamente claro que a relação entre o desenvolvimento e a democracia tem de ser vista, em parte, com relação à sua ligação constitutiva"(2011, p. 381).

Para Sen, as liberdades políticas desempenham um papel fundamental para o processo de desenvolvimento, pois "a existência de direitos políticos e civis dão às pessoas a oportunidade de chamar atenção eficazmente para necessidades gerais e exigir a ação pública apropriada". Seus estudos sobre a fome e a pobreza (Sen, 1981; Dréze e Sen, 1989) indicam que nenhuma fome coletiva jamais ocorreu em toda a história do mundo em uma democracia efetiva. Segundo Sen, isso se deve também ao fato de que as autoridades se veem compelidas a dar alguma resposta à população, quando os problemas negligenciados tornam-se objeto de debate e confrontos públicos.

Esta visão também é defendida por Barro (1996, p. 33), para quem "as instituições democráticas fornecem um instrumento de monitoramento do poder governamental, limitando a corrupção e políticas impopulares. Neste sentido, as ações do governo tornam-se respostas às pressões exercidas sobre o governo, "e é nisso que o exercício dos diretos políticos (votar, criticar, protestar, etc.) podem realmente fazer a diferença" (Sen, 2010, p. 199).

A perspectiva da liberdade também enfatiza que o processo de expansão da educação, dos serviços de saúde e outras liberdades que contribuem para a melhoria das condições de vida, incluindo 
|228|

Liberdades políticas e necessidades..

os direitos políticos e civis, não são um tipo de luxo que apenas países mais ricos podem se dar, pois representam os próprios meios e fins do desenvolvimento, incluindo o crescimento econômico.

Porém, mesmo que não fosse possível desconstruir as duas objeções anteriores sobre a preeminência do crescimento econômico em relação às liberdades políticas e aos direitos civis, o argumento em seu favor continuaria válido, pois a democracia tem importância própria na perspectiva seniana e sua negação, em si, é uma deficiência.

Nesta perspectiva, a dicotomia básica entre necessidades econômicas e liberdades políticas é insustentável, visto que a expansão das liberdades políticas interfere positivamente na indução de respostas dos governos e da própria sociedade às necessidades econômicas, devido a sua relevância intrínseca e instrumental e seu papel protetor (na promoção de discussões sobre a natureza evitável de algumas privações).

\section{Democracia e resolução de necessidades econômicas}

Sen parte da premissa de que a intensidade das necessidades econômicas aumenta - e não diminui -, a urgência das liberdades políticas e dos diretos civis básicos. Conforme Sen, "os direitos políticos, incluindo a liberdade de expressão e discussão, não desempenham apenas um papel vital na indução de respostas sociais às necessidades econômicas, mas também um papel-chave na própria conceituação das necessidades econômicas" (Sen, 2006, p. 74).

A democracia possui importância construtiva no processo de conceituação de necessidades econômicas, cuja "compreensão adequada de quais são as necessidades econômicas - seu conteúdo e sua força - requerem discussão e diálogo", uma vez que "não podemos, em geral, tomar as preferências como dadas, sem levar em conta se são ou não permitidos debates e diálogos" (Sen, 2010, p. 202).

De acordo com Anderson (2003), a concepção de democracia seniana encarna uma razão e uma experiência coletiva sobre 'como devemos viver juntos'. Neste sentido, "conversar com os outros, 
recolher e partilhar de provas e argumentos sobre o que é bom e o que funciona, está no cerne desta razão" (Anderson, 2003, p. 249). A defesa seniana da democracia assume a possibilidade de haver várias alternativas para a pergunta - como devemos viver juntos? - e conta, para isso, com o respaldado de liberdades políticas e direitos civis que tornam possível o exercício da escolha social para a formulação de respostas possíveis.
A política da democracia dá aos cidadãos a oportunidade de aprender uns com os outros e ajudar a sociedade a dar forma aos seus valores e prioridades. Mesmo a idéia de necessidades, que inclui a compreensão das necessidades econômicas, requer discussão pública e troca de informações, opiniões e análises (Sen, 2006, p. 71).

Nesta abordagem, o êxito das políticas e das estratégias de desenvolvimento envolve "a ideia do público como participante ativo da mudança, em vez de recebedor dócil e passivo de instruções ou auxílio concedido" (Sen, 2010, p. 358). Segundo Prevost (2009, p. 274), o essencial deste enfoque em relação aos seus precedentes se refere à importância que é dada ao jogo social e seus contextos específicos para determinar as capabilidades [capabilities] que serão prioritariamente valorizadas por indivíduos, grupo de indivíduos, toda uma sociedade. Desta forma, valoriza-se a democracia intrinsecamente (a partir do desenvolvimento individual em um jogo social compartido) e de forma instrumental (o aprendizado das liberdades é constitutivo da emancipação individual).

Por um lado, o enfoque seniano proporciona uma visão descritiva e compreensiva do comportamento humano e dos fatos sociais e, por outro lado, uma visão normativa formulando julgamentos de valor sobre diferentes instituições e formas de distribuição de recursos sociais, sem que, no entanto, esses julgamentos de valor suponham uma hierarquia universal. "Sen reintroduz assim uma variável ausente das teorias standard do desenvolvimento: o tempo e a história" (Prevost, 2009, 
$|230|$

Liberdades políticas e necessidades...

pp. 273-274). Trata-se uma perspectiva da história do desenvolvimento, como um movimento de experimentação e práticas relativas ao desenvolvimento da cidadania e de intuições democráticas. Sua perspectiva inclui uma reflexão que abrange uma análise da evolução de arranjos institucionais e políticos já vivenciados, e que influenciam enormemente as concepções sobre o papel da economia e os processos de institucionalização e regulação social decorrentes das diferentes concepções já adotadas.

Por este motivo, ainda que Sen defenda a preeminência das liberdades políticas e da democracia, há a consciência de que sua eficácia pode ser questionada, uma vez que a inadequação da prática aplica-se também a esse tema. Sen explica que "as realizações da democracia dependem não só das regras e procedimentos que são adotados e salvaguardados, como também do modo como as oportunidades são usadas pelos cidadãos" (Sen, 2010, p. 204). Apesar disso, Sen reafirma sua abordagem positiva da democracia como criadora de oportunidades:

A democracia não serve como um remédio automático para doenças do mesmo modo que o quinino atua contra a malária. A oportunidade que ela oferece tem de ser aproveitada positivamente para que se obtenha o feito desejado. Essa é, evidentemente, uma característica básica das liberdades em geral - muito depende do modo como elas são realmente exercidas (Sen, 2010, p. 204).

A democracia realmente cria essa oportunidade, que está relacionada tanto à sua "importância instrumental" como ao seu "papel construtivo". Mas a força com que as oportunidades são aproveitadas depende de vários fatores, como o vigor da política multipartidária e o dinamismo dos argumentos morais e da formação de valor (Sen, 2010, p. 205).

As liberdades políticas e os direitos civis são igualmente importantes para o tratamento das necessidades humanas, mesmo quando a segurança econômica está garantida, pois pessoas sem 
liberdades políticas ou direitos civis são privadas de liberdades importantes para conduzir suas vidas, sendo-lhes negada a oportunidade de participar de decisões cruciais concernentes aos assuntos públicos. A privação dessas liberdades restringe a vida social e a vida política, cerceando as oportunidades sociais criadas a partir do exercício dos direitos e liberdades políticas. Desta forma, o respaldo dessas liberdades torna-se ainda mais relevante para a resolução da insegurança econômica e da desigualdade social, principalmente, nas sociedades em que esse problema persiste de forma alarmante. Sen nos recorda que governos democráticos precisam vencer eleições e enfrentar a crítica pública, dois fortes incentivos para que tomem medidas preventivas e/ou reparadoras.

\section{O valor universal da democracia}

Na perspectiva do desenvolvimento como liberdade, a democracia possui valor universal, portanto, a crença de que as liberdades políticas, os direitos civis e a democracia representam uma prioridade especificamente ocidental é invalidada (terceiro argumento contra os direitos e liberdades políticas). Dois artigos destacam-se nessa polêmica: Democracy as a Universal Value (1999) e Why Democratization Is Not The Same As Westernization: Democracy And Its Global Roots (2003). Em ambos Sen reitera sua concepção da democracia em termos de debate público procurando demonstrar através de referências a história que valores democráticos reconhecidos, por exemplo, pluralismo, tolerância e liberdade política são conhecidos tanto do Ocidente quanto dos "estrangeiros".

Sen nos recorda que há uma tradição de debate público sobre problemas políticos, sociais e culturais na Ásia, África e no mundo árabe, populações que sofreram com a dominação autoritária de países europeus. O próprio Sen discute com outros autores, além dos clássicos de economia e filosofia política ocidentais (de Adam Smith a John Rawls), trazendo referências da cultura indiana, provérbios e parábolas orientais, etc. Autores como o poeta e intelectual bengalês Rabindranath Tagore, 
|232|

Liberdades politicas e necessidades...

laureado com o Premio Nobel de Literatura em 1913 e o Imperador mongol Akbar, que governou a Índia nos finais do século XVI, também são pensadores constantemente aludidos. Além disso, Sen lembra àqueles que se vangloriam da herança das práticas democráticas da Grécia Antiga, que os próprios gregos tinham a tendência a privilegiar relações com intelectuais indianos, iranianos e egípcios, antes mesmo que dos demais povos europeus.

Sen argumenta que a história do pensamento democrático não pode ser limitada a experiências e valores ocidentais. A democracia trata de um valor que transcende a urna eleitoral, corresponde a uma lógica de deliberação, de uma discussão e de uma razão pública. Esta concepção de democracia como um "engajamento coletivo baseado na razão prática - ou seja, o raciocínio sobre o que fazer - está no coração dos argumentos de Sen para o valor universal da democracia" (Anderson, 2003, p. 249).

Sen defende que a democracia possui valor universal, tem importância intrínseca na vida dos homens e mulheres de qualquer parte do planeta, ela desempenha papel instrumental na produção e desenvolvimento de instituições políticas e função construtiva na formação de valores e prioridades para ação coletiva permitindo um melhor conhecimento das necessidades em discussão.

Deste modo, para Sen, a democracia é compreendida como um valor universal não porque ninguém se opõe a ela, mas porque há pessoas em todos os lugares do mundo que têm razões para considerá-la dessa forma. Sendo assim, a concepção de democracia defendida por Sen encontra raízes em todas as culturas.

\footnotetext{
Algumas críticas à perspectiva seniana

Desde que foi apresentado formalmente ao público, o pensamento seniano tem provocado diferentes reações entre pesquisadores de diversas áreas. Por um lado, há certo consenso acerca dos avanços decorrentes de uma visão mais abrangente
} 
do conceito de desenvolvimento. Por outro lado, a perspectiva da liberdade trás em si aspectos que merecem ser problematizados com vista ao aperfeiçoamento dessa abordagem. Nesta seção, são mencionadas algumas apreciações críticas com relação a uma suposta concepção subjetivista em Sen.

Embora, a ênfase nas liberdades substantivas e na pluralidade de motivações para a ação humana ofereça importantes avanços para a análise das necessidades humanas, sua pertinência para a discussão sobre as relações entre liberdades, responsabilidades individuais e comprometimento social ainda é discutível. O tratamento dado ao tema da responsabilidade individual desde a perspectiva do desenvolvimento como liberdade, resulta, por um lado, em uma compreensão de responsabilidade que requer liberdades substantivas:

Sem a liberdade substantiva e a capacidade [capability] para fazer alguma coisa, a pessoa não pode ser responsável por fazê-la. Mas ter efetivamente a liberdade e a capacidade [capability] para fazer alguma coisa impõe à pessoa o dever de refletir sobre fazê-la ou não, e isso envolve a responsabilidade individual. Neste sentido, a liberdade é necessária e suficiente para a responsabilidade (Sen, 2010, p. 361).

Por outro lado, encontramos uma visão da responsabilidade individual atrelada ao compromisso social:

Indo além do nosso bem-estar ou autointeresse amplamente definidos, podemos estar dispostos a fazer sacrifícios para promover outros valores, como justiça social, nacionalismo ou bem-estar da comunidade (mesmo a um certo custo pessoal). Esse tipo de afastamento, envolvendo comprometimento (e não apenas simpatia), invoca outros valores que não o bem-estar pessoal ou o autointeresse (incluindo o autointeresse existente na promoção de interesses daqueles com quem simpatizamos) (Sen, 2010, p. 344). 
|234|

Liberdades políticas e necessidades...

Para Sen, nosso senso de responsabilidade e comprometimento não deve se restringir apenas às nossas próprias aflições, mas também relacionar-se de modo mais geral com situações em que temos condições de ajudar a remediar. "Como seres humanos competentes não podemos nos furtar à tarefa de julgar o modo como as coisas são e o que precisa ser feito. Como criaturas reflexivas, temos a capacidade de observar a vida de outras pessoas", diz Sen (Sen, 2010, p. 361). Essas capacidades nos permitem indagar sobre o quão injustas são certas disposições sociais, e sobre o que podemos fazer para tornar uma sociedade mais tolerável. Além disso, Sen argumenta que a condição de agente livre e responsável ${ }^{14}$, inclui e reconhece em seu cálculo moral, a condição de agente livre e responsável das demais pessoas.

No entanto, alguns críticos da perspectiva da liberdade consideram pouco plausíveis os encadeamentos entre responsabilidade individual e comprometimento social suscitados por Sen, por considerarem vagas e insuficientes as informações referentes ao esclarecimento dos fundamentos da escolha individual em Sen.

14 Sen explica a condição de agente livre de uma pessoa humana refere-se ao que a pessoa é livre para fazer e alcançar, em busca de quaisquer metas ou valores que ele ou ela considere importante. Um aspecto da condição de agente livre de uma pessoa não pode ser compreendido sem tomar nota das suas metas, objetivos, lealdades, obrigações e uma ampla concepção do bem. A condição de agente livre representa a liberdade para a pessoa alcançar o que quer, como agente responsável. O uso da liberdade própria do agente é, em um sentido importante, uma questão para ser julgada pela própria pessoa, a partir da necessidade de uma avaliação cuidadosa de metas, objetivos, lealdades e obrigações e - em um sentido amplo - de sua concepção do bem. A importância da condição de agente, em geral, se relaciona com a visão das pessoas como agentes responsáveis. Assim, as pessoas devem entrar na contabilidade moral de outras, não apenas como indivíduos cujo bem-estar exige preocupação, mas também como pessoas cuja condição de agente responsável deve ser reconhecida (Sen, 1985, pp. 203-204). 
De acordo com Bénicourt, Sen é muito discreto sobre como fazer escolhas individuais ${ }^{15}$. Ao apresentar sua abordagem, às vezes, ele parece evocar razões que os indivíduos podem ter para fazer escolhas baseado em uma valoração subjetivista dos estados e coisas. Segundo Bénicourt, "no nível individual, ele não sabe sobre que base os indivíduos fazem suas escolhas". Por conseguinte, Sen apresenta argumentos pouco convincentes no que se referem ao uso das liberdades políticas em prol de metas e objetivos compartidos, cujos fins podem não incidir direta ou indiretamente no aumento do bem-estar do próprio indivíduo (Bénicourt, 2007, p. 64).

\begin{abstract}
Ainda em relação às escolhas julgadas valorosas para o sujeito - indicadas por Amartya Sen -, é preciso não esquecer que o valor não é algo abstrato e atemporal, independente de sua história e de suas leis. O valor é uma categoria ontológico-social e, como tal, é algo objetivo, independente das avaliações dos indivíduos, mas não da atividade dos homens, pois é expressão e resultante das relações e situações sociais (Oliveira e Reis, 2007, p. 5).
\end{abstract}

Neste sentido, a conceituação de necessidades econômicas, por exemplo, tenderia que obedecer a algum princípio, para além da discussão pública. A interpretação de David A. Clark coincide com essa constatação. Para Clark, um dos pontos fortes do enfoque seniano deveria ser a incompletude de sua proposta, que é flexível e, portanto, apresenta um considerável grau de pluralismo interno, o que permite ver as necessidades das pessoas

${ }^{15}$ A crítica de Bénicourt não se refere aos argumentos apresentados por Sen sobre a inadequação de uma visão do comportamento humano autointeresso, mas ao fato de Sen importa-se mais em argumentar em favor da discussão pública livre e informada e enaltecer as vantagens decorrentes de acordos parciais, que em procurar fundamentar sua abordagem para além da própria discussão pública, ainda que forneça alguns critérios de objetividade e imparcialidade para a discussão. Ver: Sen ( 2011). 
|236 |

Liberdades políticas e necessidades..

de diferentes maneiras. No entanto, para Clark, é digno de nota que Sen não tenha desenhado uma lista fixa ou definitiva de funcionamentos [functionings $]^{16}$ básicos, em vez de recorrer sucessivamente ao argumento em favor da discussão pública e escolha democrática (Clark, 2007, p. 5).

De fato, o método referido por Sen para a definição e resolução de problemas morais de natureza distinta (políticos, econômicos, sociais e culturais), baseia-se na argumentação racional, que envolve a avaliação crítica dos fundamentos sobre os quais nossos juízos se apoiam. Sen sugere que há uma pluralidade de motivações para o agir humano, cuja avaliação sobre sua validade ou não como princípio, ocorre através do uso razão, alertando, somente, para o risco da desrazão (argumentação bastante primitiva e falha) (Sen, 2011, p. 63).

Ao apontar para a indispensabilidade da razão para a avaliação moral, Sen argumenta que a defesa da análise arrazoada "não depende de que esta seja uma via infalível para acertar (tal via pode nem existir), mas de que ela seja tão objetiva quanto for razoavelmente possível". Algumas pistas sobre a forma de cumprir com essa exigência de objetividade referem-se à condição de imparcialidade e razoabilidade das razões, como requisitos para a obtenção de algum grau de confiança.

Apesar de Sen desconfiar da existência de um tipo diferente de razão específica capaz de sustentar os juízos de valor, ele atribui à argumentação racional pública o status de melhor procedimento para esse fim, "ainda que não haja garantia de que ele

${ }^{16} \mathrm{O}$ conceito de funcionamentos reflete as várias coisas que uma pessoa pode considerar valioso fazer ou ser. Neste sentido, os funcionamentos são concebidos como elementos constitutivos da vida. Sen explica que os funcionamentos realizados [achieved functionings] são parte da realização de uma pessoa e servem, sob esse aspecto, como medida para a avaliação da realização do bem-estar [well-being achievement]. De acordo com Sen, "os funcionamentos valorizados podem variar dos elementares, como ser adequadamente nutrido e livre de doenças curáveis, a atividades ou estados pessoais muito complexos, como poder participar da vida em comunidade e ter respeito próprio"(Sen, 2010, p. 104). 
[o argumento moral raciocinado] será invariavelmente certo nem mesmo de que será mais certo que outros procedimentos menos arrazoados" (Sen, 2011, pp. 70-71) ${ }^{17}$.

Neste sentido, a resposta de Sen para a pergunta: como podemos julgar a aceitabilidade de certas reivindicações, recorre ao teste da razão pública. O status dessas afirmações deve passar por um escrutínio aberto e informado, a fim de proceder sua negação ou afirmação, testando assim, em em última instância, sua capacidade de sobrevivência em uma discussão desobstruída. Por este motivo, ideias como liberdades políticas e democracia, entedida como "governo por meio do debate", possuem lugar de destaque na reflexão seniana para o tratamento dado às necessidades humanas, em geral, e à noção de necessidades econômicas, em particular.

\begin{abstract}
À guisa de conclusão
Em toda sua obra, Sen preocupa-se em formular uma abordagem normativa das relações econômicas, em especial do desenvolvimento, concebida essencialmente como um processo de expansão das liberdades reais. Esta compreensão do desenvolvimento, pautado pelo valor moral substantivo da liberdade, está intimamente comprometida com a ampliação das liberdades políticas e dos direitos civis. Desde esta perspectiva, desenvolver e fortalecer os direitos políticos e civis em um sistema democrático torna-se um aspecto essencial para o processo de desenvolvimento e resolução de necessidades econômicas.

Por um lado, a perspectiva da liberdade provê os fundamentos para a preeminência de uma abordagem democrática em contraste com abordagens tecnocráticas, para a resolução de necessidades econômicas bem como sua conceituação, em políticas públicas e programas de desenvolvimento. Esta postura expõe a escolha de Sen em favor de uma razão prática e sua desconfiança em relação às formulações baseadas em valores estritos ou externos, que terminam
\end{abstract}

17 Parênteses meus. 
|238|

Liberdades politicas e necessidades...

por transcender a dimensão humana do mundo, sendo independentes "de nossas escolhas reais, nossas auto-percepções, nossos medos e esperanças" (Sen apud Crocker, 1993, p. 93).

Ao abraçar o pluralismo ético, Sen assume a incompletude de seu enfoque e enaltece o valor dos acordos mediado pela discussão pública, não como lacunas, mas como trunfos a serem utilizados no exercício da escolha social e na formulação de programas e políticas públicas mais adequados. Neste caso, o objeto da ação pública pode ser entendido como a ampliação das liberdades das pessoas para serem responsáveis pelas atividades e estados valorizados por elas.

Para Sen, devemos julgar o que é ou não valioso através de uma análise internalista. Ou seja, devemos nos perguntar que coisas são tão importantes a ponto de sem elas não considerarmos uma vida como digna de ser vivida.

A distinção instrumental - intrínseca diz respeito à questão fundamental sobre o que é considerado como valioso em si mesmo ou que deve ser visto como importante somente porque contribui para outros objetivos.

Para Sen, aquilo que melhor apreende o valor intrínseco de objetos e estados valiosos são as liberdades substantivas. Por tanto, uma investigação valorativa não tem porque ser extrema, o deslocamento da investigação da satisfação de certas necessidades, incluindo as econômicas, para o tema das liberdades fundamentais já é uma linha que conduz ao fim do caminho. Assim, "aquilo que entendemos valer a pena promover, como algo intrinsecamente valioso, será importante tanto para a análise causal como para as recomendações de política pública" (Sen apud Crocker, 1993, p. 103). Por fim, considera-se plausível as críticas referidas à perspectiva seniana sobre algumas insuficiências de sua proposta, o que não invalida as contribuições de sua interpretação em relação respeito ao destaque dado às liberdades substantivas e a importância atribuída à democracia, liberdades políticas e direitos civis como parte de uma discussão mais ampla na formação e revisão de valores sociais indispensáveis ao exame do desenvolvimento e do bem-estar, em nome de um suposto objetivismo, formulado à margem da discussão pública. 
Definitivamente, para Sen no que diz respeito aos assuntos públicos, "sem dúvida é mais importante ser vagamente correto do que precisamente errado" (Sen, 1993).

\section{Bibliografia}

ANDERSON, E. "Sen, ethics and democracy". Feminist Economics, v. 9, n. 2-3, pp. 239-261. 2003.

ARROW, K. J.; SEN, A. K. e SUZUMURA, K. (eds.). Handbook of Social Choice and Welfare. Amsterdam: Elsevier-NorthHolland, 2002.

BARRO, R. J. "Government spending in a simple model of endogenous growth". Journal of Political Economy, 98, pp. 103-125. 1990.

. Getting in right: Markets and choise in a free society. Cambridge: MIT Press, 1996.

BÉNICOURT, E. "Amartya Sen: Un bilan critique". Cahiers d'economie politique, n. 52, pp. 57-81. 2007.

CLARK, D. "The capability approach: Its development, critiques and recent advances". Global Poverty Research Group. University of Manchester, UK, 2007.

CROCKER, D. "Qualidade de vida e desenvolvimento: O enfoque normativo de Sen e Nussbaum". Lua Nova, São Paulo, n. 31, dez., pp. 99-134. 1993.

DRÉZE, J. e SEN, A. Hunger and public action. Oxford: Clarendon Press, 1989

GERSOVITZ, M. et al. The theory and experience of economic development. London: George Allen and Unwin, 1987.

HELLIWELL, J. “Empirical linkages between democracy and economic growth". Working Paper 4066, National Bureau of Economic Research, 1994. 
| 240 |

Liberdades politicas e necessidades..

KOLACINSKI, D. "Droits de l'homme et Justice Sociale. Une mise en perspective des apports de John Rawls et d'Amartya Sen". Cahier n. 01.09.24, sep. Université de Montpellier I, 2001.

MARIC, M. “Égalité et équité: l'enjeu de la liberté Amartya Sen face à John Rawls et à l'économie normative". Revue française d'économie, v. 11 n. 3, pp. 95-125. 1996.

NUSSBAUM, M. “Nature, Functioning and Capability: Aristotle on Political Distribution". Oxford Studies in Ancient Philosophy, suppl. v. 6, pp. 145-184. 1988.

. "Human functioning and social justice. In defense of Aristotelian essentialism". Political Theory, 20(2), pp. 202-246. 1992.

O'DONNELL, G. Modernization and bureaucratic authoritarianism. Berkeley: University of California Press, 1973.

OLIVEIRA, M. e REIS, C. "Conceitos e premissas sobre pobreza: Um contraponto às argumentações de Amartya Sen". In: III Jornada Internacional de Políticas Públicas: Questão social e desenvolvimento no século XXI. São Luís, MA, 28 a 30 de ago, 2007.

PREVOST, B. "Sen, la démocratie et le marché. Portée et limites d'une critique". Revue Tiers Monde, n. 198, avril-juin, pp. 269-284. 2009.

PRZEWORSKI, A. et al. Sustainable democracy. Cambridge: Cambridge University Press, 1995.

PRZEWORSKI, A. e LIMONGE, F. "Regimes políticos e crescimento econômico". Novos Estudos CEBRAP, n. 37, nov., pp. 174-189. 1997.

RAO, V. "Democracy and economic development". Studies in Comparative International Development, 24, pp. 67-81. 1984.

RAWLS, J. O liberalismo político. Tradução: Dinah de Abreu Azevedo, $2^{a}$ ed. São Paulo: Ática, 2000. 
. Uma teoria da justiça. Tradução: Almiro Pisetta e Lenita Maria Rímoli Esteves. 2a ed. São Paulo: Martins Fontes, 2002.

SEN, A. "Equality of what?". The Tanner Lecture on Human, 1979 Values, v. I. Cambridge: Cambridge University Press, pp. 197220. 1980.

Poverty and famines: An essay on entitlement and deprivation. Oxford: Clarendon Press, 1981.

"Well-being, agency and freedom: The Dewey Lectures". The Journal of Philosophy, v. 82, n. 4, Apr., pp. 169221. 1985.

. "O desenvolvimento como expansão de capacidades". Lua Nova, São Paulo, n. 28-29, abril, pp. 313-334. 1993.

"Demography and welfare economics", Empirica, 22, pp. 1-21. 1995.

. "Democracy as a universal value". Journal of Democracy, 10.3, pp. 3-17. 1999.

. Desigualdade Reexaminada. Tradução: Ricardo Doninelli Mendes. Rio de Janeiro: Record, 2001.

"Democracy and Its Global Roots: Why Democratization Is Not the Same as Westernization". The New Republic, 6 October, pp. 28-35. 2003.

La démocratie des autres. Pourquoi la liberté n'est pas une invention de l'Occident. Paris: Payot \& Rivages, 2006.

. Sobre Ética e Economia. Tradução: Laura Teixeira Motta. São Paulo: Companhia das Letras, 2008.

Desenvolvimento como Liberdade. Tradução: Laura Teixeira Motta. São Paulo: Companhia das Letras, 2010.

A ideia de Justiça. São Paulo: Companhia das Letras, 